\title{
Integrin a1 subunit is up-regulated in colorectal cancer
}

Salah Boudjadi ${ }^{1,2}$, Julie C Carrier ${ }^{1,2}$ and Jean-François Beaulieu ${ }^{1 *}$

\begin{abstract}
Background: Colorectal cancer remains one of the leading causes of death from cancer in industrialized countries. Integrins are a family of heterodimeric glycoproteins involved in bidirectional cell signaling and participate in the regulation of cell shape, adhesion, migration, differentiation, gene transcription, survival and proliferation. The a1 subunit is known to be involved in RAS/ERK proliferative pathway activation and plays an important role in mammary carcinoma cell proliferation and migration. In the small intestine, a1 is present in the crypt proliferative compartment and absent in the villus, but nothing is known about its expression in the colon mucosa, or in colorectal cancer.

Results: In the present study, we demonstrated that in the colon mucosa, a1 is present in the basolateral domain of the proliferative cells of the crypt, and in the surrounding myofibroblasts. We found higher levels of a1 mRNA in $86 \%$ of tumours compared to their corresponding matched margin tissues. Immunohistochemical analysis showed that a1 staining was moderate to high in $65 \%$ of tumour cells and $97 \%$ of the reactive cells surrounding the tumour cells vs $23 \%$ of normal epithelial cells.
\end{abstract}

Conclusion: Our findings suggest an active role for the a1 $\beta 1$ integrin in colorectal cancer progression.

Keywords: Integrin, Colorectal cancer, Tissue microarrays, Immunohistochemistry staining, QPCR

\section{Background}

Colorectal cancer (CRC) is a major public health concern in industrialized countries and remains one of the leading causes of death from cancer. Its development and progression are complex events involving many factors leading to altered expression of genes and their products. Integrins are a family of cell surface $\alpha \beta$ heterodimeric transmembrane receptors for extracellular matrix components and cell-cell interactions. These receptors play a crucial role in mediating cell signaling in response to the extracellular environment by participating in the regulation of cell shape, adhesion, migration, differentiation, gene transcription, survival and proliferation [1-3]. In this context it is not surprising to have identified integrin involvement in cancer progression. Indeed, over-expression of the $\alpha \mathrm{v} \beta 3, \alpha 5 \beta 1, \alpha \mathrm{v} \beta 5$ and $\alpha 6 \beta 4$ integrins in various cancer types and correlation

\footnotetext{
* Correspondence: Jean-Francois.Beaulieu@USherbrooke.ca

'Laboratory of Intestinal Physiopathology, Department of Anatomy and Cell Biology, Faculty of Medicine and Heath Sciences, Université de Sherbrooke, 3001 12th Avenue N, Sherbrooke, QC J1H 5N4, Canada

Full list of author information is available at the end of the article
}

with the metastatic behaviour of breast, prostate and lung cancers as well as melanomas are well documented [4]. Altered expression of integrins has also been reported in CRC [5,6]. For example, the integrin $\alpha 9 \beta 1$ was detected in $50 \%$ of the tumours [7] while expression of the pro-apoptotic $\alpha 8 \beta 1$ integrin was found to be down-regulated in CRC and the pro-proliferative variant form of the integrin $\alpha 6 \beta 4$ was exclusively found in CRC cells $[8,9]$.

Other integrins could also be involved in CRC. To date, $18 \alpha$ subunits and $8 \beta$ subunits are known to form 24 different non-covalently linked heterodimers [10]. Indeed, nothing is known about integrin $\alpha 1 \beta 1$ expression in CRC. The integrin $\alpha 1$ subunit is predominantly present in stromal and smooth muscle cells and fibroblasts and is generally absent from normal epithelia although it has been reported to be expressed in developing organs such as the kidney and skin [11]. In the human intestine, the $\alpha 1$ subunit has been found to be expressed in myofibroblasts and muscle cells as well as in a subregion of the epithelial lining, being restricted to the proliferative epithelial cell population located in the

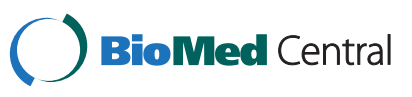




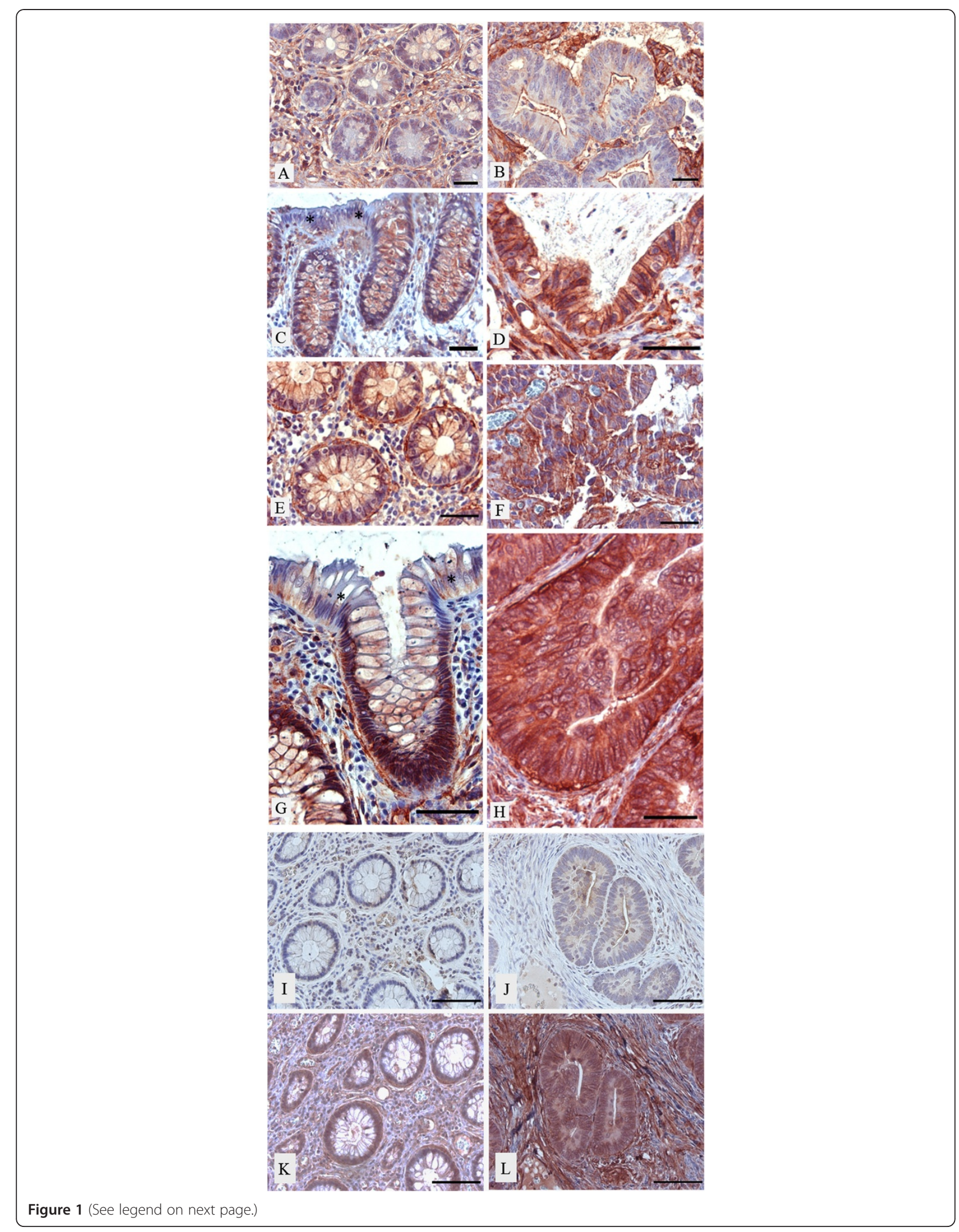


(See figure on previous page.)

Figure 1 Representative immunohistochemical images showing expression of the a1 integrin subunit in CRC (B, D, F, H, L) and corresponding matched resection margins $(\mathbf{A}, \mathbf{C}, \mathbf{E}, \mathbf{G}, \mathbf{K})$. The a1 subunit was found to be expressed at higher levels in a significant number of $C R C$ tumours $(\mathbf{D}, \mathbf{F}, \mathbf{H})$ compared to their corresponding matched normal tissues $(\mathbf{C}, \mathbf{E}, \mathbf{G})$ where it was found to be predominantly expressed in the proliferative cells of the crypt and below detection levels in normal surface epithelial cells (C, G). Note that the subepithelial myofibroblasts were also stained for a1 in both normal tissues $(\mathbf{A}, \mathbf{E}, \mathbf{G})$ and tumours $(\mathbf{B}, \mathbf{D}, \mathbf{F}, \mathbf{H})$. Scores: The margin in $\mathbf{A}$ and the tumour in $\mathbf{B}$ were both scored 0 (negative) whereas the tumour in $\mathbf{D}$ was scored 2 (strong) compared to score 0 (weak) for the matched margin $\mathbf{C}$. The tumour in $\mathbf{F}$ was scored 1 (moderate) as was its corresponding margin in $\mathbf{E}$ (moderate). The margin in $\mathbf{G}$ was scored 0 and the matched tumour in $\mathbf{H}$ was scored 2. To validate the specificity of the primary goat anti-a1 antibody, adjacent sections of the same normal $(\mathbf{I}, \mathbf{K})$ and cancer $(\mathbf{J}, \mathbf{L})$ specimens were stained using $5 \mu \mathrm{g} / \mathrm{ml}$ of non-immune $\operatorname{lgG}(\mathbf{I}, \mathbf{J})$ or anti-a1 $\operatorname{lgG}(\mathbf{K}, \mathbf{L})$ as primary antibody. Scale bars $=50 \mu \mathrm{m}$.

lower part of the glands [12,13]. Interestingly, this apparent correlation between $\alpha 1 \beta 1$ expression and the proliferative status of the cells appears to be consistent with a pro-proliferative role for $\alpha 1 \beta 1$ signaling involving the transmembrane caveolin-1, adaptor protein Shc and activation of the downstream RAS/ERK proliferative pathway $[11,14]$. These observations suggest that integrin $\alpha 1 \beta 1$ may be involved in CRC. In this study, as a first step to test this hypothesis, we investigated $\alpha 1$ integrin subunit expression in a set of colorectal adenocarcinoma specimens.

\section{Results and discussion}

In the digestive system, $\alpha 1$ integrin subunit expression in epithelia has only been reported in the small intestine and found to be confined to the lower crypts which contain the progenitor cells $[12,13]$. The integrin $\alpha 1$ subunit's $\beta$ partner, $\beta 1$, has been observed throughout the crypt-villus axis [12]. In the present study we confirmed using two distinct antibodies that, as seen in the small intestine, the $\alpha 1$ subunit was confined to crypt cells and was below the detection level in the differentiated epithelial cells of both the upper gland and surface epithelium of the normal colon (see * in Figure 1C, G and Figure $2 \mathrm{~A}$ ). In the lower half of the glands $\alpha 1$ expression was typically restricted to the basolateral domain of the epithelial cells and was also strongly expressed in the myofibroblasts [15] surrounding the crypts (Figure 1E, G, $\mathrm{K}$ and Figure 2B). Expression of $\alpha 1$ in crypt cells suggests a possible role in cell proliferation, as has been reported in mouse breast cancer [16]. As in normal epithelial cells, the $\alpha 1$ integrin subunit in cancers was localized at the basolateral domain of the tumour cells (Figure 1D, F, H). Indirect immunofluorescence on frozen tissue sections clearly confirmed the presence of the integrin $\alpha 1$ subunit in normal and tumour cells where an anti-laminin, a specific basement membrane marker [6], was used to delineate the epithelial staining from the strong mesenchymal signal (Figure 2).
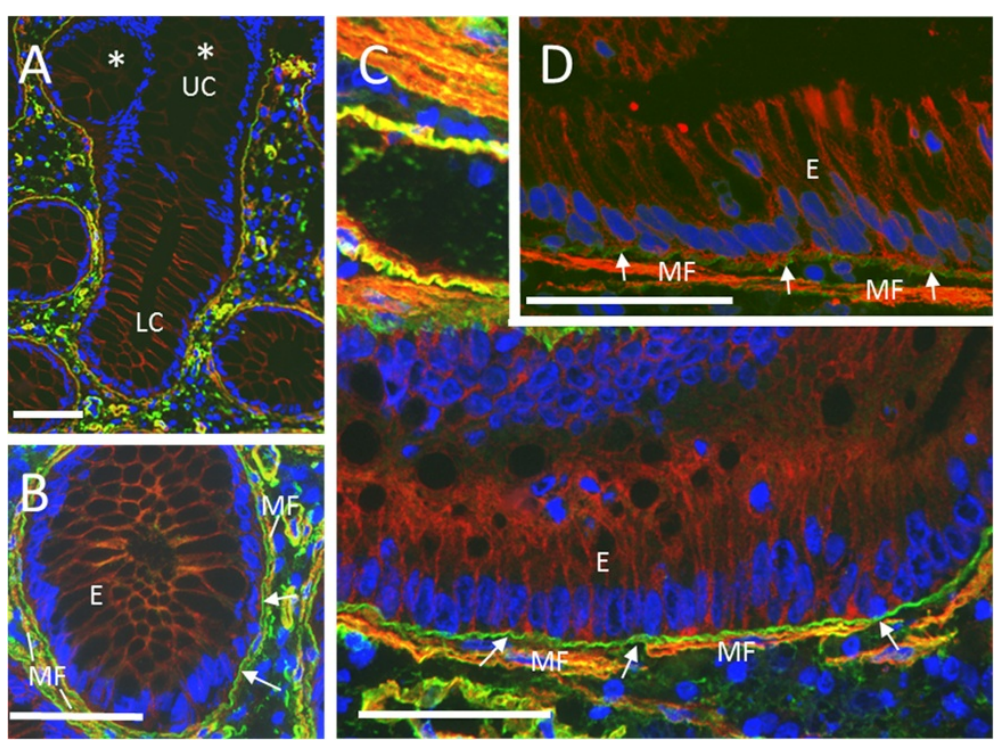

Figure 2 Representative indirect immunofluorescence images showing double-stained sections for the detection of the a1 integrin subunit and laminin in a normal colon mucosa (A and B) and a moderately differentiated colon adenocarcinoma specimen (C, D). The a1 subunit (red signal) was observed at the basolateral domain of normal epithelial cells of the lower crypt compartment (LC in panel $\mathbf{A}$ and $\mathbf{E}$ in panel B) compared to weak signal in the upper compartment (UC, panel A). In CRC, a1 was also localized at the basolateral domain of tumour epithelial cells (E) as well as in the adjacent subepithelial myofibroblasts (MF) (Panels C, D). Basement membrane (arrows) located at the interface between the two tissues was stained with an anti-laminin antibody (green staining). Nuclei were stained with DAPI (blue). Scale bar $=50 \mu \mathrm{m}$. 


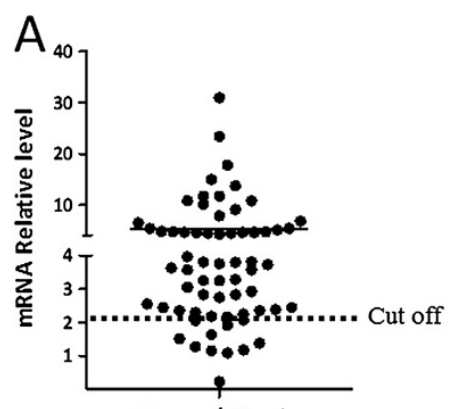

Cancer/Margin

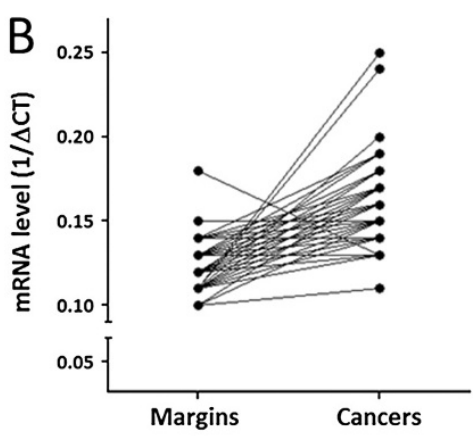

$\Delta$

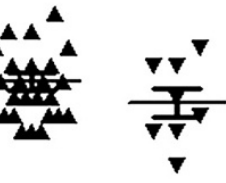

$0.10-1$

$0.05-$

Stage I Stage II Stage III Stage IV

\begin{tabular}{|c|c|c|c|c|c|}
\hline & & \multicolumn{3}{|c|}{ Cancer score } & \multirow{2}{*}{ Total } \\
\hline & & 0 & 1 & 2 & \\
\hline \multirow{3}{*}{$\begin{array}{l}\text { Margin } \\
\text { score }\end{array}$} & 0 & 20 & 20 & 10 & 50 \\
\hline & 1 & 3 & 4 & 7 & 14 \\
\hline & 2 & 0 & 0 & 1 & 1 \\
\hline \multicolumn{2}{|l|}{ Total } & 23 & 24 & 18 & 65 \\
\hline
\end{tabular}

$\mathrm{E}$

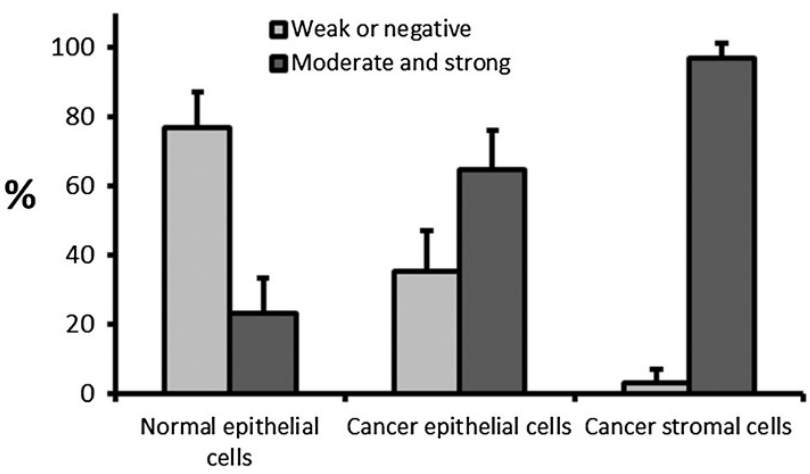

Figure 3 Expression of the $\mathbf{a} 1$ integrin subunit in CRC samples. (A) The a1 integrin subunit mRNA levels were evaluated by qPCR in 65 sets of colorectal cancers and corresponding resection matched margins. Transcript levels for a1 were found to be increased in tumours relative to their corresponding resection margins in $86 \%$ of samples (dotted line: cut off $=2$ ). Expression of the al gene was calculated by the $\Delta \Delta \mathrm{Ct}$ method and normalized to B2M expression. ( $p<0.001$, One-Sample TTest). (B) To illustrate the individual tendency of paired samples, transcript levels of a1 were expressed as $1 / \Delta C \mathrm{C}$ in each of the 65 matched margin and corresponding cancers showing the significant tendency for a higher level of expression in cancers $(p<0.001$, $t$-test two-tailed). (C) However, a1 subunit mRNA levels did not correlate with tumour stage (stage $1 ; 8$ patients, stage 2; 23 patients, stage 3; 26 patients and stage 4; 8 patients). (D) Integrin a1 expression at the protein level was analysed by immunohistochemistry on a TMA containing 65 colorectal tissues and their corresponding resection margins only considering epithelial staining. As illustrated in Figure 1, a1 immunostaining was scored as 0: negative or weak, 1: moderate or 2: strong staining. Results show that a1 staining in carcinoma vs normal epithelial cells from the matched controls was significantly higher (McNemar-Bowker's test, $p<0.001)$ in 37 specimens (57\%, gray area), similar in 25 specimens (38\%) and lower in 3 specimens (5\%). (E) The relative a1 integrin subunit expression was classified as negative/weak or moderate/strong. The results show that only $23 \%$ of the normal tissues displayed moderate/strong epithelial staining for a 1 compared to $65 \%$ of cancer cells and $97 \%$ of the peri-tumoral stromal cells. Bars represent $95 \%$ confidence level. 
Analysis of the same set of matched samples at the transcript level revealed that the mRNA levels of the $\alpha 1$ integrin subunit were significantly increased (from 2 up to 30 times) in $86.2 \%$ of the 65 adenocarcinomas studied when compared to their matched resection margins (Figure 3A and B). Similar increases were seen in all four stages studied (Figure 3C). However, based on the observations described above, the observed increase in $\alpha 1$ mRNA levels included both the tumoral and peri-tumoral tissues. Indeed, by immunohistochemistry, when considering relative protein expression only in epithelial cells, $57.0 \%$ of the tumours displayed higher expression of the $\alpha 1$ subunit than their matched resection control tissues (Figure 3D). In fact, relative expression analysis showed that only $23 \%$ of the control specimens displayed moderate/strong expression in the epithelium compared to $65 \%$ of the tumour specimens and $97 \%$ of the peri-tumoral stromal tissue (Figure 3E).

These results emphasize that integrin $\alpha 1$ subunit expression is increased in a significant proportion of both tumoral and peri-tumoral colonic tissues, a phenomenon that appears to account for the strong expression of this molecule at the transcript level. The fact that its expression is increased in $57 \%$ of the tumours relative to their matched resection margins makes the integrin $\alpha 1$ subunit a marker of interest in the context where the expression of other integrin subunits were found to be altered in comparable proportions such as $\alpha 9$ [7] and $\beta 4$ [9]. Functionally, integrin $\alpha 1 \beta 1$ has been reported to participate in cell invasion in the hepatocarcinoma model [17] and to regulate invasion by enhancing proteinase expression in a mouse mammary carcinoma cell line [16]. In vitro adhesion studies reported that integrin $\alpha 1$ blocking antibodies reduced peritoneal gastric cell invasion [18] while in the colorectal cancer HT-8/S11 cell line, $\alpha 1$, but not $\alpha 2$ or $\beta 1$ clustering induced the recruitment of the FAK/Src signaling complex involved in cell invasion [19]. It has also been reported that angiogenesis was reduced in integrin $\alpha 1$-null mice [20]. Moreover, loss of the integrin $\alpha 1$ subunit has been found to decrease the incidence and growth of lung epithelial tumours initiated by oncogenic Kras [21] consistent with the fact that Ras is a downstream effector of the $\alpha 1 \beta 1$ integrin [14] and that oncogenic changes in the Kras gene alone are not sufficient to confer a malignant phenotype [22]. Kras mutation is well known in colorectal cancer resistance to Cetuximab [23,24] but, to date, the link with $\alpha 1$ in CRC is not known.

On the other hand, it has recently been reported that cancer associated stromal cells have a pro-inflammatory gene signature [25] and promote cancer cell invasiveness [26,27]. Another study reported that fibroblasts could drive tumour mammary carcinoma progression by modulating biochemical forces through $\beta 1$ integrin signalling [28]. The data presented herein showing up-regulation of the integrin $\alpha 1$ subunit in the stromal compartment of colorectal tumours may also suggest a cooperative role of the integrin $\alpha 1 \beta 1$ in colon cancer progression.

\section{Conclusions}

In conclusion, the data presented in this study identified the expression and predominant localization of the $\alpha 1$ integrin subunit in the proliferative compartment of the normal colonic epithelium and demonstrated that $\alpha 1$ expression was significantly up-regulated in CRC in both tumour cells and surrounding stromal cells, suggesting a positive role for the $\alpha 1 \beta 1$ integrin in CRC progression.

\section{Methods}

\section{Patients, tumour tissues and tissue microarrays}

Primary colorectal adenocarcinomas and paired margin tissues were obtained from 65 patients undergoing surgical resection without prior neoadjuvant therapy. Tissues were obtained after patient's written informed consent, according to a protocol approved by the Institutional Human Subject Review Board of the Centre Hospitalier Universitaire de Sherbrooke. Staging of the adenocarcinomas was according to the TNM classification of tumours. There were 8 stage 1, 23 stage 2, 26 stage 3 and 8 stage 4 specimens. For immunohistochemistry, samples were fixed with $4 \%$ paraformaldehyde in $0.1 \mathrm{M} \mathrm{PBS}$ at $4^{\circ} \mathrm{C}$ overnight, dehydrated in graded alcohols, and then embedded in paraffin. For cryosections, tissues were embedded as previously described $[9,12]$. Total RNA was extracted from tissues using the Totally RNA kit (Invitrogen, Burlington, $\mathrm{ON}$ ) and processed according to the manufacturer's instructions $[8,9]$.

Tissue microarrays (TMA) were performed as previously described [29]. Briefly, $5 \mu \mathrm{m}$ thick serial sections were processed for routine hematoxylin and eosin staining, in order to hallmark the tissue region for TMA. Tissue cores with a diameter of $2 \mathrm{~mm}$ were removed from fixed paraffin-embedded tissue blocks using a $2 \mathrm{~mm}$ dermatological biopsy punch (Miltex Inc. York, PA) and arrayed in a paraffin mold which was first covered with double-sided adhesive to hold the cores in the correct position. Once all cores were deposited at the bottom of the mold, hot paraffin was poured to fill the mold and create a new block after incubation for one hour at $4^{\circ} \mathrm{C}$. From the new block, sections of $5 \mu \mathrm{m}$ in thickness were made. Each section was spread on a glass slide and stored at room temperature.

\section{Immunohistochemistry and expression analysis}

Sections $(5 \mu \mathrm{m}$ thick) cut from paraffin-embedded TMA were mounted on charged slides, deparaffinated in xylene and rehydrated in graded alcohol. Antigen retrieval was performed in $0.01 \mathrm{M}$ citrate buffer, $\mathrm{pH} 6$, in a microwave pressure cooker for 30 minutes. Slides were cooled to room temperature before reacting with a peroxidase blocking reagent $\left(0.3 \% \mathrm{H}_{2} \mathrm{O}_{2}\right)$ for 30 minutes, a 
streptavidin/biotin blocking reagent (Vector Laboratories Inc, Burlington, ON) for $15 \mathrm{~min}$, and blocking serum [PBS $1 \times, 0.1 \%$ BSA (Sigma-Aldrich, Oakville, ON), 0.2\% Triton X-100 (ICN Biochemicals, Aurora, OH), 0.1\% donkey serum, $0.1 \%$ goat serum] for 30 minutes. Sections were incubated overnight at $4^{\circ} \mathrm{C}$ with anti-human integrin $\alpha 1$ purified polyclonal sheep IgG $(5 \mu \mathrm{g} / \mathrm{ml}$, AF5676, R \& D Systems, Minneapolis, MN) or with equal amounts of sheep non-immune IgG (sc-2717, Santa Cruz Biotechnology, Santa Cruz, CA) as negative control, followed by incubation with an anti-sheep biotinylated secondary antibody (Vector Laboratories) for one hour at room temperature. Then, tissues were incubated with a streptavidin HRP conjugated solution (1:1000, Millipore, Billerica, MA) for one hour and the colour developed with 3,3'- diaminobenzidine (Vector Laboratories) in a buffered substrate solution. Slides were counterstained with light hematoxylin, dehydrated and cover-slipped. Representative images were acquired using a Leika DM-RXA microscope. Protein expression in different cell types, including epithelial tumour cells, epithelial normal cells and reactive cells, was separated into 2 groups based on staining intensity: negative/ low or moderate/strong expression. Expression in tumour cells was compared to the normal epithelial cells of the respective margin and scored as 0 ; no or weak staining, 1 ; moderate, and 2; strong staining.

\section{Indirect immunofluorescence}

To determine the $\alpha 1$ expression pattern, $3 \mu \mathrm{m}$ thick sections were cut from different normal colonic mucosa and adenocarcinomas samples. First, sections were fixed $10 \mathrm{~min}$ in ethanol at $-20^{\circ} \mathrm{C}$ and then washed 3 times with chilled PBS. Then, nonspecific protein-protein interactions were blocked for 30 minutes with $10 \%$ blotto followed by 2 hours incubation with the primary $\alpha 1$ mouse monoclonal antibodies TS27 (Endogen, Woburn, MA) diluted 1:10, and an anti-laminin rabbit antibody (Serotec, Raleigh, NC) diluted 1:1000 in 10\% blotto. After three washes with ice-cold PBS, slides were incubated one hour at room temperature with AlexaFluor 488 and AlexaFluor 594 conjugated secondary antibodies directed against mouse and rabbit IgG (Molecular Probe, Burlington, ON). Slides were then stained with DAPI $\left(4^{\prime}, 6-\right.$ diamidino-2-phenylindole, $2 \%$ ) and then mounted in glycerol: PBS (9:1) containing 0.1\% paraphenylenediamine and observed with a Leica DM-RXA microscope. Images were acquired and composites generated with the MetaMorph Imaging System (Universal Imaging, West Chester, PA).

\section{Real time quantitative RT-PCR}

The RNA was reverse-transcribed to cDNA with AMV reverse transcriptase (Roche, Laval, QC) following the manufacturer's instructions. Primers used to amplify $\alpha 1$ were $5^{\prime}$-CATCAGGTGGGGATGGTAAG- ${ }^{\prime}$ and 5'-TGG $^{\prime}$
CTCAAAATTCATGGTCA-3' ${ }^{\prime}$. B2M was used as housekeeping gene and primers were 5'-GTGCTCGCGC TACTCTCTC-3' ${ }^{\prime}$ and $5^{\prime}$-GTCAACTTCAATGTCGGAT$3^{\prime}$. Quantitative PCR was performed using a MX3000P Real-Time System (Stratagene, Cedar Creek, TX). $\alpha 1$ gene expression was calculated by the $\Delta \Delta C_{\mathrm{T}}$ method and normalized to B2M expression [30].

\section{Statistical analysis}

The One-Sample Student's $t$-test was used to determine the statistical significance of mRNA expression analyses. For immunohistological analyses, the McNemar-Bowker's test was used to compare scores between tumours and nonmalignant samples.

\section{Abbreviations}

CRC: Colorectal cancer; TMA: Tissue microarrays.

\section{Competing interests}

The authors declare that they have no competing interests.

\section{Authors' contributions}

SB carried out the experiments, participated in the analysis and interpretation of the data and has been involved in the drafting of the manuscript. JCC participated in the acquisition of the data and to the design of the study. JFB conceived of the study, participated in the interpretation of the data and in the preparation of the manuscript. All authors read and approved the final manuscript.

\section{Acknowledgements}

We thank Gérald Bernatchez who prepared the colorectal tissue samples and CDNA, Nuria Basora for reviewing the manuscript, Elizabeth Herring for technical support and Marie-Pierre Garant for assistance in statistical analyses The work was supported by the Canadian Institute of Health Research Grant MOP-97836 (to JFB). JFB is the recipient of the Canadian Research Chair in Intestinal Physiopathology. JFB and JCC are members of the Fonds de la Recherche en Santé du Québec-funded Centre de Recherche Clinique Étienne-Le Bel of the Centre Hospitalier Universitaire de Sherbrooke.

\section{Author details}

'Laboratory of Intestinal Physiopathology, Department of Anatomy and Cell Biology, Faculty of Medicine and Heath Sciences, Université de Sherbrooke, 3001 12th Avenue N, Sherbrooke, QC J1H 5N4, Canada. ${ }^{2}$ Department of Medicine, Faculty of Medicine and Health Sciences, Université de Sherbrooke, 3001 12th Avenue N, Sherbrooke, QC J1H 5N4, Canada.

Received: 11 December 2012 Accepted: 1 March 2013

Published: 7 March 2013

\section{References}

1. Aplin AE, Juliano RL: Integrin and cytoskeletal regulation of growth factor signaling to the MAP kinase pathway. J Cell Sci 1999, 112(Pt 5):695-706.

2. Giancotti FG: Integrin signaling: specificity and control of cell survival and cell cycle progression. Curr Opin Cell Biol 1997, 9:691-700.

3. Lock R, Debnath J: Extracellular matrix regulation of autophagy. Curr Opin Cell Biol 2008, 20:583-588.

4. Desgrosellier JS, Cheresh DA: Integrins in cancer: biological implications and therapeutic opportunities. Nat Rev Cancer 2010, 10:9-22.

5. Beaulieu JF: Integrin alpha6beta4 in colorectal cancer. World J Gastrointest Pathophysiol 2010, 1:3-11.

6. Teller IC, Beaulieu JF: Interactions between laminin and epithelial cells in intestinal health and disease. Expert Rev Mol Med 2001, 3:1-18.

7. Basora N, Desloges N, Chang Q, Bouatrouss Y, Gosselin J, Poisson J, Sheppard D, Beaulieu JF: Expression of the alphagbeta1 integrin in human colonic epithelial cells: resurgence of the fetal phenotype in a subset of colon cancers and adenocarcinoma cell lines. Int J Cancer 1998, 75:738-743. 
8. Dydensborg AB, Teller IC, Groulx JF, Basora N, Pare F, Herring E, Gauthier R, Jean D, Beaulieu JF: Integrin alpha6Bbeta4 inhibits colon cancer cell proliferation and c-Myc activity. BMC Cancer 2009, 9:223.

9. $\mathrm{Ni} \mathrm{H}$, Dydensborg AB, Herring FE, Basora N, Gagne D, Vachon PH, Beaulieu JF: Upregulation of a functional form of the beta4 integrin subunit in colorectal cancers correlates with c-Myc expression. Oncogene 2005, 24:6820-6829.

10. Barczyk M, Carracedo S, Gullberg D: Integrins. Cell Tissue Res 2010, 339:269-280.

11. Gardner H: Integrin a1ß1. In / domains in integrins. New York: Kluwer Academic/Plenum: Molecular Biology Intelligence Unit; 2003:25-39.

12. Beaulieu JF: Differential expression of the VLA family of integrins along the crypt-villus axis in the human small intestine. J Cell Sci 1992, 102(Pt 3):427-436.

13. Lussier C, Basora N, Bouatrouss Y, Beaulieu JF: Integrins as mediators of epithelial cell-matrix interactions in the human small intestinal mucosa [In Process Citation]. MicroscResTech 2000, 51:169-178.

14. Giancotti FG: Complexity and specificity of integrin signalling. Nat Cell Biol 2000, 2:E13-E14.

15. Francoeur C, Bouatrouss Y, Seltana A, Pinchuk IV, Vachon PH, Powell DW, Sawan B, Seidman EG, Beaulieu JF: Degeneration of the pericryptal myofibroblast sheath by proinflammatory cytokines in inflammatory bowel diseases. Gastroenterology 2009, 136:268-277. e263.

16. Lochter A, Navre M, Werb Z, Bissell MJ: alpha1 And alpha2 integrins mediate invasive activity of mouse mammary carcinoma cells through regulation of stromelysin-1 expression. Mol Biol Cell 1999, 10:271-282.

17. Yang C, Zeisberg M, Lively JC, Nyberg P, Afdhal N, Kalluri R: Integrin alpha1beta 1 and alpha2beta1 are the key regulators of hepatocarcinoma cell invasion across the fibrotic matrix microenvironment. Cancer Res 2003, 63:8312-8317.

18. Fukuda K, Saikawa Y, Yagi H, Wada N, Takahashi T, Kitagawa Y: Role of integrin alpha1 subunits in gastric cancer patients with peritoneal dissemination. Mol Med Report 2012, 5:336-340.

19. Van Slambrouck S, Grijelmo C, De Wever O, Bruyneel E, Emami S, Gespach C, Steelant WF: Activation of the FAK-src molecular scaffolds and p130Cas-JNK signaling cascades by alpha1-integrins during colon cancer cell invasion. Int J Oncol 2007, 31:1501-1508.

20. Pozzi A, Moberg PE, Miles LA, Wagner S, Soloway P, Gardner HA: Elevated matrix metalloprotease and angiostatin levels in integrin alpha 1 knockout mice cause reduced tumor vascularization. Proc Natl Acad Sci U S A 2000, 97:2202-2207.

21. Macias-Perez I, Borza C, Chen X, Yan X, Ibanez R, Mernaugh G, Matrisian LM, Zent R, Pozzi A: Loss of integrin alpha1beta1 ameliorates kras-induced lung cancer. Cancer Res 2008, 68:6127-6135.

22. Sato M, Vaughan MB, Girard L, Peyton M, Lee W, Shames DS, Ramirez RD, Sunaga N, Gazdar AF, Shay JW, Minna JD: Multiple oncogenic changes (K-RAS(V12), p53 knockdown, mutant EGFRs, p16 bypass, telomerase) are not sufficient to confer a full malignant phenotype on human bronchial epithelial cells. Cancer Res 2006, 66:2116-2128.

23. Lievre A, Bachet JB, Le Corre D, Boige V, Landi B, Emile JF, Cote JF, Tomasic G, Penna C, Ducreux M, et al: KRAS mutation status is predictive of response to cetuximab therapy in colorectal cancer. Cancer Res 2006, 66:3992-3995.

24. Misale S, Yaeger R, Hobor S, Scala E, Janakiraman M, Liska D, Valtorta E, Schiavo R, Buscarino M, Siravegna G, et al: Emergence of KRAS mutations and acquired resistance to anti-EGFR therapy in colorectal cancer. Nature 2012, 486:532-536.

25. Erez N, Truitt M, Olson P, Arron ST, Hanahan D: Cancer-associated fibroblasts Are activated in incipient neoplasia to orchestrate tumorpromoting inflammation in an NF-kappaB-dependent manner. Cancer Cell 2010, 17:135-147.

26. Hu M, Yao J, Carroll DK, Weremowicz S, Chen H, Carrasco D, Richardson A Violette S, Nikolskaya T, Nikolsky Y, et al: Regulation of in situ to invasive breast carcinoma transition. Cancer Cell 2008, 13:394-406.

27. Gaggioli C, Hooper S, Hidalgo-Carcedo C, Grosse R, Marshall JF, Harrington K, Sahai E: Fibroblast-led collective invasion of carcinoma cells with differing roles for RhoGTPases in leading and following cells. Nat Cell Biol 2007. 9:1392-1400.

28. Levental KR, Yu H, Kass L, Lakins JN, Egeblad M, Erler JT, Fong SF, Csiszar K, Giaccia A, Weninger W, et al: Matrix crosslinking forces tumor progression by enhancing integrin signaling. Cell 2009, 139:891-906.
29. Chen N, Zhou Q: Constructing tissue microarrays without prefabricating recipient blocks: a novel approach. Am J Clin Pathol 2005, 124:103-107.

30. Dydensborg AB, Herring E, Auclair J, Tremblay E, Beaulieu JF: Normalizing genes for quantitative RT-PCR in differentiating human intestinal epithelial cells and adenocarcinomas of the colon. Am J Physiol Gastrointest Liver Physiol 2006, 290:G1067-G1074.

doi:10.1186/2050-7771-1-16

Cite this article as: Boudjadi et al:: Integrin a1 subunit is up-regulated in colorectal cancer. Biomarker Research 2013 1:16.

\section{Submit your next manuscript to BioMed Central and take full advantage of:}

- Convenient online submission

- Thorough peer review

- No space constraints or color figure charges

- Immediate publication on acceptance

- Inclusion in PubMed, CAS, Scopus and Google Scholar

- Research which is freely available for redistribution 